2020 Global Marketing Conference at Seoul Proceedings: 981-983 (November 2020) https://doi.org/10.15444/GMC2020.07.06.02

\title{
THE ROLE OF VIRTUAL REALITY AND ARTIFICIAL INTELLIGENCE IN MARKETING RELATIONSHIP COMMUNICATIONS
}

\author{
Mó nica Ferreira, Instituto Universitá ro de Lisboa (ISCTE-IUL) and Business \\ research unit (BRU-IUL), Portugal ${ }^{1}$ \\ Sandra Maria Correia Loureiro, Instituto Universitá ro de Lisboa (ISCTE-IUL) and \\ Business research unit (BRU-IUL), Portugal ${ }^{2}$ \\ Hé lia Pereira, Instituto Universitá ro de Lisboa (ISCTE-IUL) and Business research \\ unit (BRU-IUL), Portugal ${ }^{3}$
}

\begin{abstract}
Virtual Reality (VR) and Artificial Intelligence (AI) have benefited from a constant presence in the front stage of the top technological breakthroughs due to their potential contribution in the Marketing field. This growing interest to understand the potential of VR and AI and as a new way to attract customers and enrich their experiences led to this study. Using the Integrated Marketing Communications concept, the final goal is to discuss the extent to which experiences using Virtual Reality and Artificial Intelligence may impact a customer experience in three different points of the customer journey: pre-purchase (brand associations), purchase (intention) and post- purchase stage (brand loyalty).
\end{abstract}

Firms are forcing to transform the communication process due to the proliferation of new communication tools has forced firms to choose the most appropriate combination of communication platforms to deliver a stronger message consistency and also to allocate the marketing budget over these efficiently. For such, it is necessary to adopt a "360-degree view" of consumers to get a complete and potentially full understanding of their behavior in all touchpoints with a brand (Kotler \& Keller, 2012). In the literature review, this is named as an Integrated Marketing Communication (IMC) Plan. IMC "is an audience-driven business process of strategically managing stakeholders, content, channels, and results of brand communication programs" (Kliatchko, 2008, p. 140).

To develop a well-integrated marketing communication, Kliatchko (2005) suggest three features that Nowak and Phelps (1994) introduce and are still widely stated today by other authors: consistency, complementarity and cross-effects. Consistency - the aim is to induce action where the same persuasive message and brand image is reinforced along the brand's touch points. Consistency contributes to a synergy effect, meaning that all messages connected contribute much more to brand equity and to drive sales than separate messages delivered on their own. Complementarity - determines if the communication option addresses the effects and objectives that others do not, allowing marketers to check which would be discarded if they stopped using a specific communicant option. Cross-effects - the communication effects can be enhanced when communication options are specifically designed to work together, and consumers have contact with different brand touchpoints.

\footnotetext{
monica.ferreira@iscte-iul.pt

2 sandramloureiro@netcabo.pt

3 helia.pereira@iscte-iul.pt
} 
Virtual Reality is a suite of technologies capable of placing the user inside to a simulated environment. The interaction with 3D graphics, instead of viewing a screen in front of them, is the most immediately-recognisable component of VR. With the huge advancements in this technology, VR has recently become more associated to an immersive VR experience which includes the use of a Head-Mounted-Display (HMD) to immerse the user into a complete 3D artificial world. Although, there are two additional forms of VR (Stone, 1995): Desktop-based VR - Considered the beginning of VR, where a conventional desktop monitor builds the image of an imaginary world in 3D format. Projection-based VR - A virtual reality experience is created via 3D projections from a pair of conventional video projectors, in a "CAVE".

Concerning the term of "artificial intelligence" was introduced by John McCarthy (1956) in a historic meeting at Dartmouth. Over the past 70 years, computers scientists such as Alan Turing, Claude Shannon and John McCarthy have been contributing to the development of this field. In 1950, even before the concept has emerged, Alan Turing introduced the question "Can machines think?" Later on, in 1986, Geoffrey Hinton, discover the technique behind the current excitement of AI - the deep learning - being considered "the father of deep learning" (Somers, 2017). However, due to the inefficient computer power at that time, the enthusiasm with AI was asleep temporarily and only in the last decade with the advances of technology, companies like Alphabet, Amazon, Microsoft, IBM, Facebook, Apple and three giants companies from China - Tencent, Baidu and Alibaba - have reborn the field (The Future Today Institute, 2018). Some authors say the current generation is assisting to the $4^{\text {th }}$ industrial revolution, others, named it the era of computing (The Future Today Institute, 2018). In fact, AI comes to rethink and to revolutionise the businesses processes in four domains (Microsoft \& EY, 2018)

The main findings suggest that these technologies represent valuable opportunities in Marketing and that the type of experiences addressed in this paper are more prone to instill action (purchase stage) than to build brand associations (pre-purchase stage) or brand loyalty (post-purchase stage).

Keywords: virtual reality, artificial intelligence, customer experience, integrated marketing communications.

\section{References}

Batra, R., \& Keller, K. L. (2016). Integrating marketing communications: New Findings, new lessons, and new ideas. Journal of Marketing, 80, 122-145.

Coresight Research (2018). Artificial intelligence in retail, part 1: applications across customer-facing functions. (accessed on 13 July 2018) Retrieved from https://www.fungglobalretailtech.com/research/artificial-intelligence-retail-part1-applications-across-customer-facing-

functions/?ct=t(DAILY_FEED_SEP_1_20169_1_2016_COPY_01)\&mc_cid=8 e4ea7764f\&mc eid $=5 \mathrm{a} 2 \mathrm{e} 6 \mathrm{eab} 8 \mathrm{~d}$

Coresight Research (2018). Artificial intelligence in retail, part 2: what retailers are doing with AI. (accessed on 14 July 2018) Retrieved from https://www.fungglobalretailtech.com/research/artificial-intelligence-retail-part2-retailers-ai/?mc_cid=5917905591\&mc_eid=a089bb4816

Dawar, N. (2018). Marketing in the age of Alexa. Harvard Business Review, May-June 
$18,80-86$

Harrison, K. L. (2017). Why VR is the perfect way to win gen $\mathrm{Z}$ consumers. Inc. (accessed on 12 of January 2019) Retrieved from https://www.inc.com/kate-lharrison/why-vr-is-the-perfect-way-to-woo-gen-zers.html

Kliatchko, J. (2005). Towards a new definition of integrated marketing communications (IMC). International Journal of Advertising, 24 (1), 7-34.

Kliatchko, J. (2008). Revising the IMC construct. International Journal of Advertising, 27(1), 133-160.

Kotler, P., \& Keller, K. L. (2012). Marketing Management (14 ${ }^{\text {th }}$ ed.). New Jersey: Pearson Education.

Lemon, K. N. \& Verhoef, C. P. (2016). Understanding customer experience throughout the customer journey. Journal of Marketing, 80, 69-96. 